By Arthur S. Flemming, Secretary of Health, Education, and Welfare, April 7, 1959

\title{
Indian Health
}

$\mathrm{O}$ NE of the Nation's most dramatic health stories of our time has been unfolding quietly and steadily among American Indians and Alaska natives.

I have received from Surgeon General Leroy E. Burney a report of recent progress in the Indian health program covering improvements in health and medical services to the 385,000 American Indian and Alaska native beneficiaries. This report traces health trends since 1954, immediately prior to the transfer of the program to the Public Health Service in 1955, through facts and figures available in the closing quarter of 1958. Here are some of the highlights :

- Tuberculosis, once the leading cause of death among Indians and Alaska natives, dropped a full 40 percent among the Indians in the 4-year period ended with 1957. Among Alaska natives, the decrease was even greater63 percent in the same period. This disease now ranks as the eighth cause of death among Indians, and fifth among Alaska natives.

- New cases of tuberculosis have dropped 25 percent among Indians and about 33 percent among Alaska natives.

- The Indian infant death rate has been reduced by 12 percent.

- The Indian death rate from diseases of the stomach and intestines came down by 26 percent.

This is the first report of a series to be issued regularly so that full, current information on the progress of health services to Indians and Alaska natives may be constantly available.

In calling attention to progress since 1954, neither Dr. Burney nor I wish to give the impression that this country's Indian health problems are solved. This is far from true, even with respect to tuberculosis. That disease still claims nearly four times more lives among American Indians than among the $\mathrm{Na}$ tion's general population, and upwards of eight. times more Indians contract tuberculosis. 'The tuberculosis death rate among Alaska natives is more than 10 times greater than the national average.

Health problems among American Indians and Alaska natives still are unique and severe. Language differences combined with limited understanding by Indians of health and disease concepts still constitute obstacles of considerable magnitude. Geographic and cultural isolation on some 250 Federal Indian reservations and in hundreds of native villages in Alaska, combined with an extremely low economic level, are serious handicaps in the provision of services.

The health program operates over tremendous areas in 25 States, including Alaska. Its hospital at Point Barrow, above the Arctic Circle, is the most northerly in the world. In this area, the Public Health Service has medical personnel who drive their own dogsleds and fly their own airplanes. The first operation ever performed in Alaska involving the transplanting of a cornea was on a 16-yearold Eskimo girl in the Public Health Service hospital at Anchorage in December 1958.

Distances, population dispersion, and absence of local water supplies pose severe obstacles for doctors, nurses, health educators, and sanitation personnel in the southwest. One Public Health Service dental officer travels 10,000 miles a year treating his patients on the vast Navajo reservation, which covers an area the size of West Virginia. Construction of an urgently needed new hospital for the Papagos 
on the Arizona desert was delayed for months because of difficulties in locating a water supply.

Gross and widespread environmental sanitation problems-notably lack of safe water supply and overcrowded and inadequate housing-persist as the allies of excessive disease rates. These are problems which the Indians are generally unable to correct within their own economic resources. The task ahead is still enormous.

Substantial increases in funds for Indian health during recent years have enabled the Public Health Service to make inroads against critical disease problems. Trained professional staff members, so vital to the success of a direct service operation such as the Indian health program, have been substantially increased in number. A good start has been made in eliminating the generally unsatisfactory condition of Indian health facilities and the shortage of modern medical equipment.

Notable progress also has been made against trachoma, the infectious eye disease which still exists in this country among Indians. Dr. Phillips Thygeson, internationally recognized authority on this disease, serves as the Public Health Service's consultant in planning and developing trachoma control activities. His "Trachoma Manual and Atlas" published last year by the Service is, I am told, a valuable aid in the diagnosis and treatment of trachoma not only among Indians but in other countries where this disease is a major health problem.

Although Indian infant deaths dropped 12 percent in the 4 years ended with 1957, the Public Health Service recognizes that the present rate of 57 deaths per 1,000 live births is excessively high. Increasing numbers of Indian babies are born in the Service's Indian hospitals, and as a result the Indian infant death rate in the first month of life now compares favorably with that of the general population. However, because of unfavorable environment, Indian infants die at more than five times the rate for the population as a whole during the succeeding 11 months of life.

We will never be satisfied until the health of the Indians is fully comparable with that of most Americans. It is our aim not only to hold present gains but to increase our efforts in this field.

\section{New Reports on Death Rates}

A new series of 62 reports presenting age-specific and ageadjusted death rates is being released by the National Office of Vital Statistics, Public Health Service. The series, Vital Statistics-Special Reports Volume 49, is entitled "Death Rates for Selected Causes by Age, Color, and Sex: United States and Each State."

These reports include both age-adjusted and age-specific rates for the average of the 3 years 1949, 1950, and 1951.

With the exception of No. 1, which summarizes data on death from all causes, each number contains data for a single cause of death or group of related causes. The reports follow the classifications in the "Manual of the International Statistical Classification of Diseases, Injuries, and Causes of Death." Thirty of the series have already been released, and the remainder are scheduled for publication during 1959 .

Copies are available from National Office of Vital Statistics, Public Health Service, Washington 25, D.C. 